\title{
LAS NOVELAS DE MARIO VARGAS LLOSA: UNA TEOLOGÍA DEL PODER
}

\begin{abstract}
Alonso Cueto
Este ensayo presenta una visión de la obra de Vargas Llosa a partir de la relación entre sus personajes y el poder. La tesis del autor es que los personajes de Vargas Llosa viven para ejercer respuestas individuales frente a las presiones de una realidad opresiva, marcada por los designios de lo todopoderoso. De este modo, en Vargas Llosa toda forma de realidad se encuentra marcada por una condena ontológica. El poder es el pecado original de una realidad inescapable. Según el autor, los personajes de Vargas Llosa protagonizan el drama vital de buscar dos respuestas al poder: la rebeldía y el sueño.
\end{abstract}

Alonso Cueto (Lima, 1954) es profesor asociado de la Universidad Católica del Perú y miembro de la Academia Peruana de la Lengua. Su obra incluye trece libros de narrativa, dos libros de ensayos y una obra teatral. En 2000 fue galardonado con el Premio alemán Anna Seghers por el conjunto de su obra narrativa y el año 2005 obtuvo el Premio Herralde por su novela La hora azul (2005). En 2007 fue primer finalista del Premio Planeta Casa América por El susurro de la mujer ballena. Su novela Grandes miradas fue llevada al cine por Francisco Lombardi. Alonsocuetocaballero@yahoo.com.

Estudios Públicos, 122 (otoño 2011). 
Ta obra de Vargas Llosa es una gran exploración narrativa sobre el poder. En el universo de Vargas Llosa, el poder es la única garantía de supervivencia social, la clave a través de la cual se accede a la supremacía, en un universo marcado por la ley de la violencia. Sin embargo, el instinto de poder no es sólo social o político. Aparece también en las relaciones íntimas que mantienen sus personajes, en sus afectos $\mathrm{y}$ amores privados, en sus rencores, en sus ambiciones y deseos. Sus novelas, ensayos y obras de teatro giran en torno a los efectos que tiene en nosotros vivir en un universo definido en su origen por los designios del poder. En este universo los poderosos, es decir los más violentos, se imponen a los demás. La historia es narrada siempre por sus víctimas, pues el narrador (y el autor) siempre están de su lado. Para Vargas Llosa, la historia del poder está contada desde el lado de las respuestas de los oprimidos.

Frente al poder, con frecuencia ejercido por un líder pero también por un sistema social o incluso por la realidad misma, el individuo tiene dos respuestas. Una de ellas es social y puede definirse como la rebeldía, con frecuencia marcada por el sueño utópico colectivo. La otra es privada y se encarna en las utopías privadas del arte, la religión y el amor. Alberto, Jum, el Conselheiro y Flora Tristán pertenecen al primer grupo. El Escribidor, Gauguin, Rigoberto y la niña mala, al segundo. En todos estos casos, sin embargo, la división no es absoluta, pues ambas respuestas con frecuencia coexisten en sus personajes, como veremos luego.

En los protagonistas de Vargas Llosa la respuesta al poder social o político es la formulación de un nuevo poder, un ejercicio alternativo. La conclusión es evidente: para enfrentar al poder, el individuo necesita de su propia cuota de poder (real o ilusorio). No hay una forma inocente de enfrentarse a una realidad marcada por un poder anónimo y brutal.

$\mathrm{Si}$, como dice Zavalita en Conversación en La Catedral, el universo social está dividido entre "quienes joden" y "quienes son jodidos", entonces las relaciones entre los seres humanos están definidas por una voluntad natural de dominio. El poder no es sólo un mecanismo de inserción en la colectividad o una condición del dominio político. Su necesidad también impregna las relaciones privadas. En obras como Elogio de la madrastra, Las travesuras de la niña mala, o Cuadernos de don Rigoberto, la sexualidad, el amor e incluso el afecto son insepa- 
rables de algún impulso esencial de dominio, como bien lo sabe Ricardo, el personaje que vive en manos de la niña mala.

$\mathrm{Si}$ alguna conclusión se desprende de sus obras es que esta relación con el poder en cualquiera de sus formas (político, erótico, doméstico y familiar) define de un modo decisivo la identidad de sus personajes. En el rebaño de lo humano, el instinto por el poder siempre encumbra a unos líderes que crean en torno a ellos un macroclima social, basado en su predominio. Nadie es ajeno al poder del líder. Todos deben definir qué hacen, qué dicen, a quién aman, a quién desean, a quién odian, qué esperan y a qué le temen, en suma quiénes son, de acuerdo a la existencia del líder o del sistema poderosos. Tanto el instinto de la obediencia como el de la rebelión son impulsos derivados de la existencia de un todopoderoso. El modo como los rayos del poder se refractan en la comunidad, afectan las fibras más íntimas de los individuos que pertenecen a ella, su vida privada y familiar, es la premisa desde la cual se genera el universo de sus novelas.

El tema del poder está ligado, por lo tanto, al de la rebeldía. En cada novela de personaje hay un líder pero hay también uno o más rebeldes. La perspectiva del rebelde es esencial a las obras de Vargas Llosa. Gran parte de su obra es un homenaje al heroísmo del rebelde como un confrontador, pero también un elogio al soñador, como un evasor y un creador.

\section{El fuego transgresor}

Si los personajes de Vargas Llosa (el Esclavo, el Jaguar, Pantaleón, Flora Tristán, etc.) sienten la violencia del poder, su respuesta va a ser la rebeldía. Pero la ecuación entre el líder y el rebelde no agota su problemática. La rebeldía, para serlo realmente, toma la forma de otro poder, un poder alternativo que crea a su vez una sociedad (el Círculo, las células de estudio marxistas, la comunidad del prostíbulo perfecto en la Amazonía). El rebelde, por lo tanto, se convierte en un poderoso en sus obras, es decir se transfigura en el mismo ser que combate. El Jaguar se rebela contra las autoridades del colegio pero termina siendo más violento que ellos. Pantaleón se rebela contra el ejército pero sigue sus códigos de organización y disciplina y convierte a las visitadoras en sus soldados. El Conselheiro se rebela contra la República pero forma su propia comunidad de militantes. Lo mismo hace Roselli, con su 
comunidad de cruzados que buscan defender los balcones coloniales. El rebelde es un poderoso que con frecuencia ejerce el poder con más autoridad que aquel contra el cual se rebela. En esta paradoja podemos deducir que el instinto por ostentar el poder, de algún modo, es esencial a sus personajes. Todos los transgresores se vuelven, o aspiran a volverse, poderosos. Ésta es una paradoja trágica que termina por diluirlos. El fin de muchos de estos poderosos o de rebeldes es el olvido. Es el final de Mayta o del Jaguar o de los Cachorros.

Si la obra de Vargas Llosa es una exploración en la problemática del poder, es en consecuencia también una exploración sobre los límites de la libertad. La rebeldía puede ser vista como un apogeo de la libertad frente al poderoso. Ejercer la libertad frente al poderoso se convierte en un dilema trágico para sus personajes, como ocurre con Alberto al denunciar al Círculo en La ciudad y los perros. Pero tanto el poder como la rebeldía, para serlo, necesitan de un tiempo y un espacio. El poder crea un espacio ilusorio. El Jaguar es poderoso dentro de las cuadras del colegio pero su poder se va a terminar al final del periodo escolar, cuando sale al mundo y se casa. Pantaleón tiene el poder en la medida en que navegue el espacio de la selva con las visitadoras, pero su tiempo está limitado a la llegada de las sanciones de sus superiores. Cayo Bermúdez tiene el poder cuando accede a las oficinas del Ministerio, pero antes de eso, en el tiempo anterior, era un pobre diablo que se ganaba la vida como podía. El poder como creador de un espacio y un tiempo sagrados, el espacio y el tiempo del líder, es esencial a su visión del poderoso.

Frente al ejercicio o a los abusos del poder, es decir en el riesgo, en el peligro, sus personajes adquieren su identidad. Son quienes son en el acto de rebelión. La rebeldía es un definidor. Del Alberto de $L a$ ciudad y los perros al Roger Casement de El sueño del celta, los personajes de Vargas Llosa muestran a un autor obsesionado por definir a sus personajes en el ejercicio de la transgresión, la rebeldía, la libertad.

\section{Un dominio natural}

El mundo (o al menos el mundo de sus novelas) se origina en un acto de dominio, parece pensar Vargas Llosa. No es posible imaginar una vida, cualquier tipo de vida social, familiar, institucional o erótica, que no esté marcada por el instinto de poder. 
Uno de los ejemplos más significativos es la primera escena de La ciudad y los perros, cuando el dado marca el número cuatro, y nos enteramos de que el Cava es el encargado de robar el examen para el Círculo:

—Cuatro — dijo el Jaguar.

Los rostros se suavizaron en el resplandor vacilante que el globo de luz difundía por el recinto, a través de escasas partículas limpias de vidrio: el peligro había desaparecido para todos, salvo para Porfirio Cava. Los dados estaban quietos, marcaban tres y uno, su blancura contrastaba con el suelo sucio.

—Cuatro — repitió el Jaguar-. ¿Quién?

- Yo - murmuró Cava-. Dije cuatro.

—Apúrate —replicó el Jaguar-. Ya sabes, el segundo de la izquierda ${ }^{1}$.

El pasaje introduce a un narrador omnisciente, que asiste a la reunión de los miembros del Círculo y aparece en un espacio cercano a ellos. En esa mirada exterior, que no toma partido en el inicio por la conciencia de ninguno de los personajes, el narrador crea un clima de fatalismo marcado por los dados que eligen al Cava. Una construcción oximorónica ("resplandor vacilante") define un juego de oposiciones en el escenario. Las "escasas partículas limpias" y la blancura de los dados contrastan con el "suelo sucio". El alivio de los demás cadetes contrasta con la tensión en el rostro del Cava.

En este espacio de claridades, oscuridades y contrastes, la voz del Jaguar diciendo "Cuatro" (la primera línea de la novela) es algo así como la voz del destino. Cuando ese destino se expresa en el Jaguar, quien parece encarnarlo, se produce el primer hecho de una cadena. La escena de los dados es, por lo tanto, una premisa de la historia.

Los cadetes han decidido que quien salga sorteado va a robar el examen. Pero esa decisión pertenece al Jaguar. Cuando los dados salen, el Jaguar solamente le recuerda a Cava los datos de la realidad. El poder natural del Jaguar es anterior a los hechos, pertenece a un universo original. No necesita, por lo tanto, dar o repetir una orden.

En esta primera escena de La ciudad y los perros, por lo tanto, los dados tienen la fuerza de un acto de creación del mundo. Todo parece haber sido decidido. La historia acaba de adquirir una dirección. El énfasis que pone el autor en la inmovilidad de los dados ("estaban quie-

\footnotetext{
${ }^{1}$ La ciudad y los perros [1963], 2001, p. 7.
} 
tos"), la suma fatal de sus cifras ("marcaban tres y uno") y el contraste entre su blancura definida y el "resplandor vacilante" del globo de luz, señalan, en medio de sus contradicciones, una orden primordial. En este momento, Cava sabe que no tiene ninguna opción frente a la autoridad del Jaguar que respalda el azar de los dados. El Jaguar no le indica la acción que debe realizar (robar el examen), pues ésta es sobreentendida. Solamente le ofrece unas indicaciones operativas, basándose en su autoridad, en el imperativo ("Apúrate") y la confirmación del lugar ("Ya sabes, el segundo de la izquierda").

El "ya sabes" es en particular una señal que apunta a una referencia anterior, un recordatorio de todas las instrucciones previas entre ellos (ya les ha dicho dónde queda el lugar de donde van a robar). Pero es también una alusión al sistema de autoridad y de poder que el Jaguar ha creado, antes de los hechos que narra la novela. Cuando la novela empieza, el Jaguar ya ha sido investido de la autoridad. "Ya sabes" es una frase mágica en el líder, pues le recuerda al subordinado la composición esencial del mundo en un sistema de lealtades y obediencia. El nexo entre el jefe y su subordinado está apuntalado en esta frase. El "saber" al que se refiere el Jaguar no solamente es la ubicación del lugar donde debe robar el examen. Se refiere también a la conciencia ("ya sabes") por parte de Cava de todo el conjunto de relaciones entre él y el Jaguar que hace necesario que él le obedezca.

El acto fundacional de la novela es, por lo tanto, una orden que no admite réplica. Los dados fijos señalan un destino tan inquebrantable como la frase del Jaguar, "Ya sabes". El Cava sabe dónde queda el lugar donde debe robar el examen pero también sabe que no hay escapatoria posible a su misión. Se encuentra cargado de una misión que debe asumir:

Cava sintió frío. Los baños estaban al fondo de las cuadras, separados de ellas por una delgada puerta de madera, y no tenían ventanas. En años anteriores, el invierno sólo llegaba al dormitorio de los cadetes, colándose por los vidrios rotos y las rendijas; pero este año era agresivo y casi ningún rincón del colegio se libraba del viento, que, en las noches, conseguía penetrar hasta en los baños, disipar la hediondez acumulada durante el día y destruir su atmósfera tibia. Pero Cava había nacido y vivido en la sierra, estaba acostumbrado al invierno: era el miedo lo que erizaba su piel$^{2}$.

\footnotetext{
${ }^{2}$ La ciudad y los perros [1963], 2001, p. 7.
} 
La descripción del espacio es en cierto modo la de una cárcel a la intemperie. Todo lo que separa a los cadetes del frío es precario. La "delgada puerta de madera", la falta de ventanas, los "vidrios rotos", las rendijas, son construcciones endebles y al mismo tiempo son los muros de una cárcel. El narrador desvía la atención hacia el frío del Cava atribuyéndolo en apariencia al clima desprotegido del recinto. Aunque luego va a concluir que no era el frío sino "el miedo lo que erizaba su piel", el recurso ya le ha servido para introducirnos en el recinto que rodea a los cadetes. Aquí también hay un sistema de contrastes, entre el viento frío, la "hediondez acumulada" y la "atmósfera tibia". El universo de Vargas Llosa está constituido por la convivencia de los contrarios. El frío y lo cálido, la oscuridad y la luz, el blanco y el negro: polos entre los cuales sus personajes sufrirán existencias entregadas a sus extremos. El poder y la rebeldía van a encontrar un escenario natural en este entorno. En un mundo marcado por los límites máximos, la lucha, el desafío van a marcar las conductas.

El frío y el miedo son indicadores de la inmensa soledad de Cava. El azar lo ha convertido en un ser marginal, un personaje que acepta el orden del universo en que ha nacido, incapaz de rebelarse. Cava está marcado por el lugar que tiene en la estructura del colegio y en la del Círculo, la de ser un subordinado. El hecho de que sea serrano lo remite, asimismo, al fondo de la estructura de la sociedad peruana. El miedo de Cava, que le eriza la piel, contrasta con la firmeza del Jaguar. Este contraste entre ambos tiene un contexto en las relaciones entre el blanco y el negro de lo que los rodea: los dados blancos contra la suciedad del suelo. Desde entonces, en una cadena de causas y consecuencias, se establece la secuela perversa de la novela: Cava rompe una luna al robar el examen, las autoridades descubren la falta y castigan a los cadetes los fines de semana, el Esclavo que quiere ver a Teresa denuncia al Círculo, el Círculo mata al Esclavo, el Poeta denuncia al Jaguar, etc.

No es casualidad que La ciudad y los perros se inicie con un acto de mando y de obediencia. Estos ocurren en el círculo privado del poder de los cadetes y se rigen bajo sus códigos. Pero esta sumisión de parte de Cava no ocurre solamente en relación con el Jaguar sino a partir de su relación con el mundo, la de ocupar un lugar en su estructura inamovible. En ese sentido el Jaguar, como cualquier dictador, busca congelar el tiempo. Frente a él, Alberto va a tratar de movilizarlo. A lo largo de la novela, cuando la acción se traslada a otros dos cadetes, 
como el Esclavo y Alberto, la relación entre el subordinado y el poder va a transformarse. A diferencia del Cava que es un sumiso, el Esclavo es un delator y Alberto va a convertirse en un rebelde. El arco del héroe enfrentado al poder va a irse marcando hasta llegar a su escena crucial, la del encuentro entre el Jaguar y Alberto en la celda, donde se produce la lucha entre ambos.

Esta percepción del poder como un hecho inscrito en la realidad no es, por lo tanto, ajena a la que anima a Santiago Zavala cuando se pregunta "en qué momento se había jodido el Perú". Las reglas de la realidad ya están establecidas. Son parte de la naturaleza. Están inscritas en ella. En el inicio de La ciudad y los perros y de Conversación en La Catedral todo parece estar sobreentendido.

En el mundo de Vargas Llosa, como en el de Balzac (tal como éste planteó su visión de la sociedad en el famoso prólogo a La Comedia Humana), las personas sólo tienen la opción de ejercer o sufrir el dominio del poder. La clave de esta visión del mundo aparece en el vocablo "joder" o "ser jodido".

Toda búsqueda de poder, como hemos visto, necesita de sus propios espacios y tiempos. El poder es inseparable de una señalización en el tiempo y en el espacio. Pantaleón Pantoja es un heredero del Jaguar, pues busca un tiempo fluido - el barco, el río-, donde se plantean espacios itinerantes - las guarniciones-, a las que el poder se traslada. El Círculo del Jaguar se repite en la comunidad de las visitadoras, que actúan al margen del poder oficial, al servicio de un poder alternativo, el de Pantaleón. Es evidente que Pantaleón es un líder risueño y amable, que se enamora de una de las visitadoras, pero su juego, el de construir un poder alternativo al del poder central, es similar al que ocurre en La ciudad y los perros. El ideal de Pantaleón es el de una comunidad utópica, una aspiración que no es distinta al sueño de la utopía social de Flora Tristán y del Conselheiro e incluso al Círculo del Jaguar.

El poderoso para serlo, por tanto, requiere de su propia comunidad de seguidores. El Jaguar se enfrenta al poder ejerciéndolo en el Círculo. El Conselheiro se enfrenta al poder ejerciéndolo en los Canudos. Flora Tristán se enfrenta al poder tratando a su vez de ejercerlo a través de su influencia en los movimientos sociales del siglo XIX. Bruno Roselli ejerce la marcha de los cruzados en El loco de los balcones contra el poder de quienes quieren traerse abajo los balcones coloniales. 
Sin embargo, en la obra de Vargas Llosa, esta respuesta frente al poder, la del rebelde, con frecuencia es aplastada. Los rebeldes de Vargas Llosa, desde Alberto y el sargento Gamboa hasta Casement, pasando por el Conselheiro, Jum, Zavalita y Mayta, son aplastados por el poder central o por sus propias insuficiencias.

\section{El entorno y la voluntad}

En este contexto, la representación del entorno físico como un espacio opresor que destruye o limita la libertad de los personajes es un tema recurrente en la obra de Vargas Llosa, especialmente en sus primeras novelas. El recinto sombrío, apenas iluminado por un globo de luz que aparece al comienzo de La ciudad y los perros, como una cárcel que desafía la voluntad de sus habitantes, reaparece con variantes en el pasaje inicial de La Casa Verde. En ese primer pasaje de la novela, mientras el sargento "echa una ojeada" a la Madre Patrocinio y "el moscardón sigue allí", una sombrilla de jejenes escolta la lancha y entre los cuerpos "evolucionan mariposas, avispas, moscas gordas". A continuación el práctico Nieves se pregunta: "Estos selváticos no eran normales, ¿por qué no sudaban como los demás cristianos?"

La selva opresiva, hostil, extraña define la relación con el entorno para los protagonistas de la novela. Tanto el práctico Nieves como el sargento se perciben como ajenos, unos exilados en la naturaleza amazónica. En una operación similar a la de La ciudad y los perros, el entorno es percibido como un espacio ajeno al individuo, un espacio de confrontación. Esa misma operación puede verse en el inicio de Conversación en La Catedral.

Desde la puerta de La Crónica Santiago mira la avenida Tacna, sin amor: automóviles, edificios desiguales y descoloridos, esqueletos de avisos luminosos flotando en la neblina, el mediodía gris. ¿En qué momento se había jodido el Perú? Los canillitas merodean entre los vehículos detenidos por el semáforo de Wilson voceando los diarios de la tarde y él echa a andar, despacio, hacia La Colmena. Las manos en los bolsillos, cabizbajo, va escoltado por transeúntes que avanzan, también, hacia la plaza San Martín. El era como el Perú, Zavalita, se había jodido en algún momento. Piensa: ¿en cuál? ${ }^{3}$

${ }^{3}$ Conversación en La Catedral [1969], 2001, p. 13. 
Tanto el colegio militar en La ciudad y los perros como la Avenida Tacna en Conversación en La Catedral son espacios carcelarios. La Avenida Tacna que Santiago mira "sin amor" es percibida, al igual que las cuadras del colegio militar, como un encierro. Los "edificios desiguales y descoloridos", "esqueletos de avisos luminosos flotando en la neblina", "el mediodía gris" parecen llevar, en una secuencia fatal a la pregunta de la novela que es asimismo su conclusión: ¿En qué momento se había jodido el Perú?

Por otro lado, la imagen del individuo frente al entorno puede definirse por la postura de Zavalita ("echa a andar, despacio...", "Las manos en los bolsillos, cabizbajo") y por una afirmación que define la ecuación entre el individuo y el entorno del que parte la novela: "El era como el Perú, Zavalita, se había jodido en algún momento".

La acumulación de evidencias de un entorno urbano opresivo, caótico y hostil (la Avenida Tacna) recuerdan la atmósfera sombría y sucia de la cuadra del colegio militar en La ciudad y los perros y el espacio inclemente de la selva en el inicio de La Casa Verde. Todo lo que sigue en el pasaje inicial de Conversación en La Catedral no parece sino enfatizar esta ecuación esencial entre el destino de los personajes y las presiones del entorno.

El entorno hostil, enajenante que aparece en estas novelas iniciales no es del todo distinto al que encuentra Urania cuando vuelva a su país en el inicio de La fiesta del Chivo:

La superficie azul oscura del mar, sobrecogida por manchas de espuma, va a encontrarse con un cielo plomizo en la remota línea del horizonte, y, aquí, en la costa, rompe en olas sonoras y espumosas contra el Malecón, del que divisa pedazos de calzada entre las palmeras y almendros que lo bordean. [...] Entonces la imagen le devuelve el recuerdo del día en el que entra al restaurante del hotel Jaragua, donde está ahora, con su padre, para "almorzar los dos solos"

La ciudad de Santo Domingo, una pesadilla de la memoria, reaparece de un modo insistente, lo mismo que el antiguo local del hotel (que ha sido reemplazado por uno nuevo). La ciudad se ha llenado de barrios, avenidas, parques y hoteles pero ella está segura de que su casa apenas ha cambiado con su "pequeño jardín, el viejo mango y el flam-

\footnotetext{
${ }^{4}$ La fiesta del Chivo [2000], 2001, p. 12.
} 
boyán de flores rojas recostado sobre la terraza donde solían almorzar al aire libre los fines de semana; su techo de dos aguas y el balconcito de su dormitorio, al que salía a esperar a sus primas Lucinda y Manolita, y, ese último año, 1961, a espiar a ese muchacho que pasaba en bicicleta, mirándola de reojo, sin atreverse a hablarle" 5 .

Esta relación entre el personaje y su entorno físico, de raigambre romántica, es constante en la obra de Vargas Llosa. Como hemos visto, con frecuencia el entorno es percibido como un ambiente hostil, siniestro, opresivo, frente al cual se resalta la figura del héroe individual.

La cuadra del colegio en La ciudad y los perros, la Avenida Tacna en Conversación en La Catedral, la capital de Santo Domingo en La fiesta del Chivo, son espacios malignos que definen la identidad de los individuos a los que rodean. El hecho de que estas novelas se inicien con una descripción del entorno es en cierto modo una afirmación de la relación profunda que el entorno tiene sobre el personaje y los hechos perversos de la historia. De acuerdo a su herencia romántica, el medio es determinante en la naturaleza de los personajes y las situaciones que viven bajo su dominio. La frase final del primer capítulo de Conversación en La Catedral ("la miserable garúa de siempre"), parece referir a una identidad esencial del entorno ("de siempre") que condiciona a sus individuos y define sus historias. Ninguna forma de redención, de inocencia es posible bajo las condiciones que marca este entorno.

Vargas Llosa, por lo tanto, en estas novelas concibe los espacios como encierros. El encierro del colegio en su primera novela equivale al encierro de la ciudad en Conversación en La Catedral. Oprimidos, encerrados por una realidad primordial, los personajes están a merced de su poder. Los espacios son sistemas activos de la realidad, no meros escenarios o decorados. Hay en su diseño una perversión original que ha aprisionado a los héroes. Frente a ellos, como frente a cualquier forma de poder, queda la rebelión o el arte. Son los caminos del guerrillero o del novelista.

\section{El cuerpo como registro de la violencia}

Una de las constantes en las novelas de Vargas Llosa es su pasión por la exploración minuciosa de los cuerpos como expresiones de la identidad de los personajes. Algunas de estas descripciones van

\footnotetext{
${ }^{5}$ La fiesta del Chivo [2000], 2001, p. 13.
} 
adosadas a los diálogos, en lo que constituye un salto del narrador de un registro del habla del personaje a una percepción simultánea de su aspecto. En el inicio de La ciudad y los perros, luego del encargo que recibe Cava, aparece el Boa:

— ¿Se acabó? ¿Puedo irme a dormir? — dijo Boa: un cuerpo y una voz desmesurados, un plumero de pelos grasientos que corona una cabeza prominente, un rostro diminuto de ojos hundidos por el sueño. Tenía la boca abierta, del labio inferior adelantado colgaba una hebra de tabaco. El Jaguar se había vuelto a mirarlo ${ }^{6}$.

Si el narrador describe al Boa con ese aspecto desmesurado, de tono expresionista, la mirada del Jaguar aparece para domesticarlo. Si el Boa quiere irse a dormir, basta que el Jaguar lo mire para devolverlo a su papel de subordinado. La desmesura del cuerpo y el rostro del Boa no pueden atentar contra el poder del Jaguar. Los rasgos del Boa están hechos de contrastes ("cabeza prominente" y "rostro diminuto", "cuerpo y voz desmesurados" y "ojos hundidos por el sueño"), que construyen el aspecto de un ser deformado y grotesco. Ésta es la definición del Boa, vista desde la óptica del narrador que va a definir su conducta a lo largo de la novela. La identidad del Boa está atada a su cuerpo. En las novelas de Vargas Llosa, el cuerpo es una seña esencial de la identidad de sus personajes.

Una de las descripciones físicas más logradas sin duda es el primer párrafo de La guerra del fin del mundo. La primera definición del cuerpo del Conselheiro ("era tan flaco que parecía siempre de perfil”) parece definir su naturaleza sagrada. Esta definición implica evidentemente la naturaleza religiosa del Conselheiro, cuyo cuerpo parece estar siempre apuntando al cielo. El relato de las acciones del personaje parece derivarse de su descripción:

El hombre era alto y tan flaco que parecía siempre de perfil. Su piel era oscura, sus huesos prominentes y sus ojos ardían con fuego perpetuo. Calzaba sandalias de pastor y la túnica morada que le caía sobre el cuerpo recordaba el hábito de esos misioneros que, de cuando en cuando, visitaban los pueblos del sertón bautizando muchedumbres de niños y casando

${ }^{6}$ La ciudad y los perros [1963], 2001, p. 7. 
a las parejas amancebadas. Era imposible saber su edad, su procedencia, su historia, pero algo había en su facha tranquila, en sus costumbres frugales, en su imperturbable seriedad que, aun antes de que diera consejos, atraía a las gentes ${ }^{7}$.

Una vez más, en esta descripción se aplica la técnica de rasgos con contrastes visuales. La oscuridad de la piel contrasta con el fuego de los ojos y la forma del cuerpo "alto y tan flaco que parecía siempre de perfil" contrastan con sus "huesos prominentes" y sus ojos que "ardían con fuego perpetuo".

Por otro lado, la novela sigue una estructura clásica pues se inicia con una descripción y luego con las acciones del personaje, en la tradición del inicio del Quijote. De hecho, la descripción de Vargas Llosa parece tomar como modelo la de Cervantes para transformarla. Si en la página inicial de su novela Cervantes habla de "complexión recia, seco de carnes" y de una edad ("frisaba la edad de nuestro hidalgo en los cincuenta años"), Vargas Llosa toma este modelo de descripción no para crear una familiaridad con el personaje sino precisamente para hacerlo más extraño: "Era imposible saber su edad, su procedencia, su historia". Esta extrañeza sobre el origen está compensada por los efectos de su conducta: "atraía a las gentes". Vargas Llosa parece proceder por un sistema que vincula una conducta a un aspecto.

El inicio de La guerra del fin del mundo por otro lado es en cierto modo un homenaje a las convicciones de la frenología, es decir la pasión de Galileo Gall, pues asimila las acciones a la apariencia física del protagonista. Uno no puede imaginar al Conselheiro sino como un hombre con el aspecto que describe. La descripción es una premisa de su conducta, de la narración.

La pasión por el cuerpo humano en la obra de Vargas Llosa tiene una vertiente sombría en sus descripciones de víctimas muertas y mutiladas. Una de las más famosas es sin duda la del comienzo de ¿Quién mató a Palomino Molero?:

El muchacho está a la vez ahorcado y ensartado en el viejo algarrobo, en una postura tan absurda que más parecía un espantapájaros o un Ño Carnavalón despatarrado que un cadáver. Antes o después de matarlo lo habían hecho trizas, con

${ }^{7}$ La guerra del fin del mundo, 1981, p. 15. 
un ensañamiento sin límites: tenía la nariz y la boca rajadas, coágulos de sangre reseca, moretones y desgarrones, quemaduras de cigarrillo, y, como si no fuera bastante, Lituma comprendió que también habían tratado de caparlo, porque los huevos le colgaban hasta la entrepierna. Estaba descalzo, desnudo de la cintura para abajo, con una camisita hecha jirones. Era joven, delgado, morenito y huesudo. En el dédalo de moscas que revoloteaban alrededor de su cara relucían sus pelos, negros y ensortijados. Las cabras del churre remoloneaban en torno, escarbando los pedruscos del descampado en busca de alimentos y a Lituma se le ocurrió que en cualquier momento empezarían a mordisquear los pies del cadáver ${ }^{8}$.

La magnitud de este crimen está ligada a la descripción del cuerpo como una huella de la violencia. El cuerpo es el rastro inmóvil, definido, irrefutable del acto violento. El cuerpo mutilado representa en ese sentido la congelación del espacio de la violencia. Vargas Llosa describe con minuciosidad todos los elementos de la huella violenta en el cuerpo. La descripción va del rostro ("nariz y boca rajadas"), la entrepierna ("los huevos le colgaban hasta la entrepierna" y los pies ("estaba descalzo, desnudo de la cintura para abajo..."). Luego de pasar por el cuerpo de arriba hacia abajo hay una descripción general: "joven, delgado, morenito y huesudo."

El cuerpo es, por lo tanto, un registro de la violencia. En este caso, el autor de la muerte es un ser anónimo (la incógnita de ¿Quién mató a Palomino Molero? nunca se resuelve), pero la víctima cobra una fuerza inusitada. El narrador toma el punto de vista de Lituma pero actúa como un narrador objetivo. A partir de entonces, toda la novela empieza a girar en torno del cuerpo mutilado de Palomino Molero. La pregunta del título (“¿Quién mató a Palomino Molero?”), nunca resuelta, queda enfatizada en la descripción de la víctima.

En La ciudad y los perros el cuerpo también se convierte en el objeto de la agresión. El Esclavo sufre precisamente porque quiere mortificar y modificar su cuerpo:

Su cuerpo no respondía ni esquivaba los golpes; debió esperar que el otro se cansara de pegarle. Era para castigar a ese cuerpo cobarde y transformarlo que se había esforzado en

${ }^{8}$ ¿Quién mató a Palomino Molero?, 1986, p. 5. 
aprobar el ingreso al Leoncio Prado; por ello había soportado esos veinticuatro meses largos 9 .

Si el cuerpo de la víctima es un registro de su posición en el mundo, el cuerpo del victimario se convierte asimismo en un instrumento de la autoridad. Es así que Alberto intuye al Jaguar:

Ladeando un poco la cabeza, Alberto podía ver sus grandes botines, sus gruesas piernas, su vientre apareciendo entre las puntas de la camisa caqui y el pantalón desabotonado, su cuello macizo, sus ojos sin luz ${ }^{10}$.

Una expresión más acabada del reconocimiento del cuerpo como señal de autoridad ocurre en otras novelas como en La fiesta del Chivo:

El Generalísimo, en su escritorio, lucía un uniforme que Antonio no recordaba: guerrera blanca y larga, de faldones, con abotonadura de oro y grandes charreteras de dorados flecos sobre la pechera, de la cual pendía un multicolor abanico de medallas y condecoraciones. Llevaba un pantalón azul claro, de franela, con una raya blanca perpendicular. Se dispondría a asistir a alguna ceremonia militar. La luz de la lamparilla iluminaba la cara ancha, cuidadosamente rasurada, los cabellos grises bien asentados y el bigotito mosca, imitado de Hitler (a quien, le había oído decir alguna vez Antonio, el Jefe admiraba "no por sus ideas, sino por su manera de llevar el uniforme y presidir los desfiles"). Aquella mirada fija, directa, clavó a Antonio en el sitio apenas cruzó el umbral ${ }^{11}$.

El cuerpo del subordinado, en cambio, aparece registrado claramente, como ocurre con Abbes García:

Tenía encima, rozándolo, la cara abotargada, los ojos de párpados caídos, de tortuga, de Abbes García ${ }^{12}$.

Pero el cuerpo no es sólo señal del poder del victimario o de la sumisión de la víctima sino también de la obra del mayor verdugo de

${ }^{9}$ La ciudad y los perros [1963], 2001, p. 124.

${ }^{10}$ La ciudad y los perros [1963], 2001, p. 114.

${ }^{11}$ La fiesta del Chivo, 1986, p. 118.

${ }^{12}$ La fiesta del Chivo [2000], 2001, p. 321. 
todos: el paso del tiempo. La obsesión de Rigoberto por su cuerpo (y su necesidad de estar a la altura de las necesidades de Lucrecia) es un ejemplo de cómo busca detener el tiempo, para conservarlo. Su necesidad de satisfacer a Lucrecia lo obliga a una serie de rituales de embellecimiento corporal frente al espejo.

El mismo terror al deterioro se presenta en el narrador colectivo de Los cachorros. Esta novela define también a los cuerpos en relación con la identidad. El cuerpo de Pichula Cuéllar está precisamente definido por su carencia, la falta de su órgano sexual, que en el mundo de Vargas Llosa se convierte en la falta de su virilidad. La falta del sexo es una señal de debilidad en un universo definido por el poder, es decir el sexo. Pichula Cuéllar es un paria, un hombre sin sexo, con un cuerpo reducido. No es de extrañar que los órganos sexuales aparezcan con frecuencia como símbolo de la mutilación esencial en el comienzo de ¿Quién mató a Palomino Molero? y en las torturas a los conspiradores en La fiesta del Chivo (donde uno de ellos es obligado a comerse sus órganos sexuales). El cuerpo deteriorado del Chivo, quien es incapaz de una erección en la escena con Urania Cabral joven, es una señal que anticipa su fin. No es distinto el camino que llevan los protagonistas de Los cachorros tal como aparecen en el último, melancólico pasaje del relato:

Eran hombres hechos y derechos ya y teníamos todos mujer, carro, hijos que estudiaban en el Champagnat, La Inmaculada o el Santa María, y se estaban construyendo una casita para el verano en Ancón, Santa Rosa o las playas del sur, y comenzábamos a engordar y a tener canas, barriguitas, cuerpos blandos, a usar anteojos para leer, a sentir malestares después de comer y de beber y aparecían ya en sus pieles algunas pequitas, ciertas arruguitas ${ }^{13}$.

\section{El cuerpo como registro del deseo}

La lectura del cuerpo como registro del deseo tiene también abundantes ejemplos en la obra de Vargas Llosa. En el capítulo seis de ¿Quién mató a Palomino Molero?, el sargento Silva y Lituma miran con los prismáticos a Adriana, especialmente cuando ésta se quita la

${ }^{13}$ Los cachorros [1967], 2001, p. 153. 
ropa para entrar al mar: "Lituma pudo verle los muslos, gruesos como troncos de laurel, y los pechos que sobresalían hasta la orilla misma del pezón"14. El cuerpo de Adriana es una obsesión para Lituma y el sargento Silva así como el de la madrastra lo es para don Rigoberto. El cuerpo es un botín del deseo. El que desea poseer sexualmente al cuerpo ajeno, como ocurre con La Chunga y la deseada Mechita, se convierte en un depredador, es decir en alguien que encarna el poder. El deseo sexual es un instrumento del poder que se presenta como una expresión violenta. Desear, poseer y violar un cuerpo ajeno se convierte en un acto de afirmación. El cuerpo de la víctima de ese modo es un registro del poder, una evidencia de su posición en el universo.

La historia de Las travesuras de la niña mala es la historia del cuerpo como una fantasía del deseo. Su protagonista es una mujer que cambia de cuerpo. La niña mala ofrece diferentes identidades. Su vida está dedicada a poder transmutarse en otro cuerpo, a ser otra gracias a la total enajenación de su aspecto y su voz, en cierto sentido también de su personalidad. Sus transformaciones - pasa de ser peruana a ser chilena, después japonesa y luego inglesa, etc.- y el vestirse y hablar como tales son la realización de una utopía del cuerpo múltiple, la noción de todos los cuerpos en uno. Con ello, la niña mala realiza en la vida aquello que Ricardo hace en su obra como traductor. Traductor de libros, Ricardo se convierte en un agente que transforma las palabras de un idioma en palabras de otro. La niña mala realiza un proceso más radical: convierte su cuerpo, y su vida, en otros. A diferencia de Ricardo que realiza la transformación de las palabras, ella realiza la transformación de las realidades. Es capaz de realizar en la vida aquello que Ricardo sólo puede hacer en las palabras.

Las travesuras de la niña mala es la historia del dominio, es decir la historia del poder de una mujer sobre un hombre, a través del amor. El rol que cumplen muchos tiranos y dictadores violentos en otras novelas se transfiere a la niña mala en el plano íntimo. Sin embargo, la diferencia con las figuras autoritarias de las otras novelas (el Jaguar, Trujillo o Cayo Bermúdez) es que la niña mala no tiene una sola identidad. Tiene muchas. Cambia de nombre y de identidad. Tiene siempre otro cuerpo. Es otra. Y sin embargo, en esta historia de cuerpos transformados, hacia el final de la novela, su cuerpo aparece precisamente

14 ¿Quién mató a Palomino Molero?, 1986, p. 111. 
como el registro de la enfermedad y la muerte, cuando Ricardo descubre su enfermedad en las marcas de las cirugías.

La niña mala es una heredera del Escribidor y de Gauguin pero también de Trujillo y del Jaguar. Es el intento por oponer a la crudeza de la realidad, la variedad del sueño, pero también es una dominadora implacable. Ella inventa el sueño como realidad - en una operación que no es ajena a la de Madame Bovary_- y trata de habitarlo. Pero somete a Ricardo, en el mundo real, que es incapaz de rebelarse a ella.

Hay que recordar, a propósito de la obsesión por el cuerpo en la obra de Vargas Llosa, que Gauguin es pintor de cuerpos. Pantaleón Pantoja usa los cuerpos como materiales de su utopía. El Jaguar es el dueño de los cuerpos de los miembros del Círculo. Las descripciones de Queta y de Hortensia en Conversación en La Catedral están llenas de alusiones a sus cuerpos desnudos. Por otro lado Roger Casement, lo sabemos a través del narrador, se siente fascinado por los cuerpos de los muchachos que puede ver en la Amazonía:

Uno de ellos, el más joven, era muy hermoso. Tenía un cuerpo alargado y atlético, músculos que asomaban en su espalda, sus piernas y brazos con el esfuerzo que hacía. Su piel oscura, algo azulada, brillaba de sudor. Con los movimientos que hacía al desplazarse con la carga al hombro desde la carreta al interior del depósito, el ligero pedazo de tela que llevaba envuelto en la cadera se abría y dejaba entrever su sexo, rojizo y colgante y más grande que lo normal. Roger sintió una oleada cálida y urgentes deseos de fotografiar al apuesto cargador ${ }^{15}$.

Como en el caso de Lituma y el sargento Silva, este pasaje muestra la mirada como un agente de posesión erótica. La descripción minuciosa, que supone un ejercicio de posesión visual, se convierte en una suma de contrastes (el brillo de la piel oscura, el juego entre el rojo del sexo y el azul de la piel) que eleva el cuerpo a la categoría de objeto sagrado del deseo. Esta prosa visual, cargada de elementos que definen al personaje por sus colores y formas, registra el cuerpo anhelado, como una expresión del deseo, es decir del poder. No es casual que el poder de la mirada se quiera resolver en una fotografía, como ocurre al final del pasaje.

${ }^{15}$ El sueño del celta (Madrid: Alfaguara, 2010), p. 113. 
En torno al deseo, el cuerpo se convierte en un templo privado de los amantes. No en balde leemos en Elogio de la madrastra que el sultán manda ejecutar a uno de sus sirvientes que casualmente vio el cuerpo desnudo de su esposa. La devoción de Rigoberto hacia su esposa Lucrecia se traduce en una adoración a su cuerpo. El cuerpo es un altar y a la vez un campo de exterminio.

\section{El sexo, el amor y el poder}

La sacralización y la demonización del cuerpo como expresiones del poder y del deseo son operaciones constantes en la narrativa de Vargas Llosa. Sin embargo, las fronteras que dividen el poder del deseo erótico no son claras. Con frecuencia, el deseo erótico y el deseo de poder se confunden, como puede verse fácilmente en La Chunga o en Las travesuras de la niña mala. A su vez, el poder político de Trujillo se expresa en la posesión sexual en La fiesta del Chivo.

Una prueba del cuerpo como objeto simultáneo del poder y del deseo puede encontrarse en uno de los pasajes de La ciudad y los perros. Alberto está escribiendo las novelitas que va a vender. Es una de las primeras señales de la relación del cuerpo como un agente de apetencia y posesión sexual.

"Tenía las piernas gordas, blancas y sin pelos. Eran ricas y daba ganas de morderlas". Alberto se quedó mirando la frase, tratando de calcular sus posibilidades eróticas, y la encontró bien ${ }^{16}$.

Las "posibilidades eróticas" de la frase que escribe Alberto pueden extenderse a muchos pasajes en la obra de Vargas Llosa. En general, los cuerpos que prefieren sus personajes son parecidos a los de Adriana, grandes, ampulosos y, en palabras de Lituma, "bien despachados". No es casualidad que los cuerpos de Botero hayan estimulado la imaginación de Vargas Llosa en sus ensayos sobre el pintor colombiano ${ }^{17}$.

\section{La violencia original}

Esta percepción de la realidad como un espacio maligno del poder, que se expresa en el deseo y la destrucción de los cuerpos, responde

${ }^{16}$ La ciudad y los perros, p. 130.

17 "Botero en los toros", diario El País, 6 de septiembre de 1992. 
a su visión de una realidad esencialmente violenta. En una declaración que cita Luis Harss, Vargas Llosa afirmaba:

Yo creo que en un país como el mío la violencia está en la base de todas las relaciones humanas. Se halla omnipresente en todos los instantes de la vida de un individuo. El individuo se afirma, se consolida socialmente venciendo resistencias de toda índole ${ }^{18}$.

\section{El sagrado poder}

El poder ocupa un lugar sagrado en la obra de Vargas Llosa. Es el centro en torno al cual convergen las voluntades y limitaciones de sus personajes. Estos ostentan o transgreden o evaden el poder, o hacen todo ello al mismo tiempo. El deseo, la violencia, la transgresión, el sueño, giran en torno al poder como situación original de la vida social y privada. En ese sentido, es la fuente esencial de su universo narrativo, la fuente sagrada en torno a la cual convergen sus habitantes.

Exploración de la violencia y del deseo, de la violencia del deseo, y del deseo de la violencia, la obra de Vargas Llosa es por eso mismo una exploración de los límites de la libertad. En sus novelas los seres humanos parecen buscar las experiencias extremas en su ejercicio del poder o en su lucha contra el mismo. El cuerpo como un registro de la violencia y el deseo, de la plenitud y el deterioro, es sin embargo sólo una huella de una vocación esencial. Lo que sus novelas muestran es la esencial insatisfacción de los seres humanos, su hambre permanente de transgresión, su vocación por explorar los límites. El poder y, frente a él la rebelión o el sueño, aparecen así como los elementos de un universo en constante movimiento. Nada en este mundo está detenido. Los personajes de Vargas Llosa siempre están insatisfechos con el poder propio o el ajeno. Buscan extremar el propio o destruir el ajeno y al mismo tiempo realizar una fuga a través del arte, el erotismo y el amor. Si hay algo que anima a sus personajes es una sed primitiva de buscar siempre nuevos mundos, en la realidad o fuera de ella. La violencia y el deseo son las armas esenciales con las que cuentan para esta gesta esencial.

Si el poder, la rebelión y el sueño pueblan las novelas de Vargas Llosa, se debe a que el impulso de sus personajes es la insatisfacción. Si

${ }^{18}$ Luis Harss, Los nuestros, 1966, p. 432. 
hay algo que iguala a Alberto, al Esclavo y al Jaguar, a Trujillo y a Urania, a Flora y a Gauguin, es su necesidad de traspasar los límites que los confinan. Lo mismo puede decirse de todos sus personajes hasta el caso ejemplar de Roger Casement. Vargas Llosa concibe a los seres humanos como unas voluntades inquebrantables, apuntando siempre a una nueva dimensión, que se ponen a prueba en la incandescencia de la lucha por y contra el poder.

Pero si Vargas Llosa ve la realidad como una permanente lucha, su corazón para siempre estará del lado de los rebeldes, de los transgresores, de los poetas Alberto, de los Jum, de los Conselheiro de este mundo. Los rebeldes y los soñadores, los transgresores y los artistas, hacen que la vida, para él, tenga un sentido y una dirección. El fuego de la transgresión es inseparable del de la novela. Es el antiguo alimento de los héroes.

\section{REFERENCIAS}

Harss, Luis. Los nuestros. Buenos Aires: Editorial Sudamericana, 1966.

Vargas Llosa, Mario. La ciudad y los perros [1963]. Lima: Peisa, El Comercio, 2001.

- Los cachorros [1967]. Lima: Editorial Peisa, 2001.

- Conversación en La Catedral [1969]. Lima: Ediciones Peisa, 2001.

- La guerra del fin del mundo [1981]. Barcelona: Editorial Seix Barral, 1981.

¿Quién mató a Palomino Molero? [1986]. Barcelona: Editorial Seix Barral, 1986.

- "Botero en los toros", diario El País, 6 de septiembre de 1992.

- La fiesta del Chivo [2000]. Madrid: Alfaguara.

El sueño del celta [2010]. Madrid: Alfaguara, 2010. 